\title{
MASTICATION AND SWALLOWING: INFLUENCE OF FLUID ADDITION TO FOODS
}

\author{
Luciano José PEREIRA ${ }^{1}$, Maria Beatriz Duarte GAVIÃO² ${ }^{2}$, Lina ENGELEN ${ }^{3}$, Andries Van der BILT ${ }^{3}$
}

\author{
1- DDS, MSc, PhD, Full Professor, Department of Clinical Dentistry, Dental School of Três Corações, University of Vale do Rio Verde \\ (UNINCOR), Três Corações MG, Brazil. \\ 2- DDS, MSc, PhD, Full Professor, Department of Pediatric Dentistry, Dental School of Piracicaba, State University of Campinas (FOP/ \\ UNICAMP), Piracicaba SP, Brazil. \\ 3- MSc, PhD, Research Fellow, Department of Oral and Maxillofacial Surgery, Prosthodontics and Special Dental Care, Oral Physiology \\ Group, University Medical Center, Utrecht, The Netherlands.
}

Corresponding address: Luciano José Pereira - Rua Horácio de Carvalho, 125 - Lavras, MG, Cep.: 37200-000 - e-mail: luciano@fop.unicamp.br phone: $+55-35-38213040$

Received: July 17, 2006 - Modification: December 14, 2006 - Accepted: February 22, 2007

\begin{abstract}
I

ntroduction: The production of sufficient saliva is indispensable for good chewing. Recent research has demonstrated that salivary flow rate has little influence on the swallowing threshold. Objectives: The hypothesis examined in the present study was that adding fluids to foods will influence chewing physiology. Materials and Methods: Twenty subjects chewed on melba toast, cake, carrot, peanut and Gouda cheese. They also chewed on these foods after addition of different volumes of water or $\alpha$-amylase solution. Jaw muscle activity, number of chewing cycles until swallowing and chewing cycle duration were measured. Repeated measures analysis of variance was applied to test the null hypothesis that there would be no statistically significant difference among the results obtained for the various food types and fluids. Subsequently, contrasts were determined to study the levels of intra-subjects factors (food type and fluid volume). Linear regression was used to determine the changes in muscle activity and cycle duration as a function of the chewing cycles. Results: Fluid addition significantly decreased muscle activity and swallowing threshold for melba, cake and peanut $(\mathrm{p}<0.05)$. The effect of $\alpha$-amylase in the solutions was similar to that of water $(\mathrm{p}>0.05)$. Doubling the volume of tap water had a greater effect. Conclusions: Fluid addition facilitated chewing of dry foods (melba, cake), but did not influence the chewing of fatty (cheese) and wet products (carrot). This study is relevant to improve patients' life quality and the management of chewing and feeding disorders caused by hyposalivation.
\end{abstract}

Uniterms: Saliva; Mastication; Swallowing; Food; Muscle activity.

\section{INTRODUCTION}

Chewing is the first step in the process of digestion and is meant to prepare the food for swallowing and further processing in the digestive system. During chewing, the food bolus or food particles are reduced in size. The water in the saliva moistens the food particles, whereas the salivary mucins bind masticated food into a coherent and slippery bolus that can be easily swallowed ${ }^{21}$. The urge to swallow can be triggered by a threshold level in both food particle size and lubrication of the food bolus ${ }^{11,22,23}$.

Large differences exist among subjects with respect to both masticatory performance $\mathrm{e}^{6,12}$ and salivary flow rate $5,7,8,16,27$. However, these differences are not or are only very weakly correlated with the number of chewing strokes needed to prepare the food for swallowing ${ }^{5,6}$. Thus, an individual with a good masticatory performance does not necessarily swallow food at a smaller number of chewing strokes than a subject with a worse masticatory performance.
As a consequence, good chewers would, on average, swallow finer food particles than bad chewers. Furthermore, a subject with a relatively high salivary flow rate does not necessarily swallow food after less chewing cycles than a subject with a lower salivary flow rate ${ }^{5}$. This means that individuals with high salivary flow rates are used to swallowing better moistened food. A previous study conducted at Utrecht Laboratory has also shown no relationship between salivary flow rate and sensory ratings ${ }^{4}$. Subjects with higher salivary flow rate during eating did not rate food differently from subjects with lower salivary flow. This finding could indicate that subjects are used to their respective amount of saliva in such a way that the differences in sensory ratings between subjects cannot be explained by the inter-individual difference in salivary flow rate. However, an artificial increase of $0.5 \mathrm{~mL}$ saliva significantly influenced the sensory ratings of semisolids ${ }^{4}$. While saliva and food have been shown to influence the chewing process, the relationship between the amount of saliva and 
mastication has not been extensively studied ${ }^{9}$.

The effect of fluid addition to solid foods on the chewing process is unknown. Therefore, the aim of the present study was to investigate the influence of adding fluids (tap water or $\alpha$-amylase solution) on chewing physiology: muscle activity, number of chewing strokes until swallowing and cycle duration. Different types of foods were used: hard and dry melba toast, soft and dry cake, hard and wet carrot, hard and fat peanut and soft and fat cheese.

\section{MATERIALAND METHODS}

\section{Subjects}

Twenty healthy subjects ( 15 females and 5 males) aged 19 to 41 years (mean age $=24.8 \pm 6.3$ years) were enrolled in this study. All volunteers had natural dentition at least up to the second molars without evident defect of dental structures, periodontal problems or severe malocclusion. The subjects were assigned to either a morning or an afternoon group based on their availability. Each subject was always tested at the same time of the day. The Ethics in Research Committee of the University Medical Center Utrecht approved the study design and protocol. Written informed consent was obtained from all subjects after a full explanation of the experiment.

\section{Test Foods}

The following natural foods were used, all of them with the same calculated volume $\left(8 \mathrm{~cm}^{3}\right)$ : melba toast (Melba toast, Buitoni, Italy, www.buitoni.com), breakfast cake (Right, Peijnenburg, the Netherlands, www.right.nl), carrot, peanut and Gouda cheese. The physical characteristics of the natural foods (e.g. density, water and fat percentages and yield point) have been previously published ${ }^{5}$.

\section{Procedure}

The subjects chewed on the 5 foods while different volumes of tap water $(5$ and $10 \mathrm{~mL})$ and $\alpha$-amylase solution (5 mL; bacillus subtilis - Sigma-Aldrich, St Louis, MO, USA) were added. As a control, the subjects also chewed the foods without fluid addition. It was chosen $\alpha$-amylase activity of $200 \mathrm{U} / \mathrm{mL}$, which is of the same magnitude observed during chewing ${ }^{16}$. The $\alpha$-amylase solution was prepared freshly prior to each experiment. The amount of fluid added were based on the saliva secretion in response to food stimulation ${ }^{7,8}$. The liquids were added to the mouth right after the food. During two 1-hour sessions (at 2 separate days), the subjects were presented with duplicates of the samples. All combinations of fluids, volumes and foods were administered in a random order. The subjects were asked to chew on the food in their usual manner until they wanted to swallow. They were free to swallow the food or split it out into a container after chewing.

In addition to water, one of the contents of saliva are the mucins, which cover and protect the oral cavity ${ }^{15,25}$. Mucins are also responsible for the lubricating properties of saliva and facilitate manipulation, mastication and swallowing of foods ${ }^{26}$. In the present study, the addition of mucincontaining artificial saliva ( $5 \mathrm{~mL}$; Saliva Orthana, Nycomed, Little Chalfont, UK) to food was also tested. However, the obtained data were excluded from the study because the unexpected bad taste of Saliva Orthana experienced by all subjects led to inconsistent and highly variable results for all parameters. Taste cognition can modify food mastication ${ }^{19}$. As taste is a subjective factor, it may induce different individual's responses, which may explain the large variance of the results.

\section{Jaw movement and surface electromyography}

During all chewing sequences, the jaw gape was measured by recording the position of two infrared light emitting diodes (one on the chin and one on the forehead) with an optical motion analysis system (Northern Digital Optotrak $^{\circledR}$; www.ndigital.com). The electrical activity of the masseter and the anterior temporalis muscles was recorded using bipolar electrodes (Blue sensor, Medicotest, Ølstykke, Denmark). The electromyographic (EMG) signals were amplified and sampled at $1500 \mathrm{~Hz}$. Off-line, the EMG signals were full-wave rectified and filtered (low pass $35 \mathrm{~Hz}$ ). The maximum amplitude and the area of the EMG bursts were determined for all chewing cycles of each muscle. The values for the left and right masseter and temporalis muscles were then summed. The movement signal was used to determine the cycle duration for each chewing cycle and the number of chewing cycles until swallowing.

\section{Statistical Analysis}

Repeated measures analysis of variance (ANOVA SPSS 9.0; SPSS Inc., Chicago, IL, USA) was applied to test the null hypothesis that there would be no statistically significant difference among the results obtained for the various types of foods and fluids. Subsequently, contrasts were settled to assess the levels of the intra-subjects factors (food type and fluid volume). Linear regression was used to determine the change in muscle activity and cycle duration as a function of the chewing cycles. Again, repeated measures ANOVA was used to test the influence of food and fluid on the change of these parameters during chewing. Significance level was set at $5 \%$.

\section{RESULTS}

Repeated measures ANOVA showed a significant influence on the various physiological parameters of both food typeS and added fluids (Table 1). There was also statistically significant interaction between food and fluid $(p<0.05)$, which means that the effect of adding a fluid to a food is not consistent for the different foods. Therefore, the influence of fluid addition on the physiological parameters for each food was also examined separately (Table 2). The effect of food and fluid on muscle activity and swallowing threshold is shown on Figure 1.

The type of food had a strong significant effect on muscle activity, number of chewing cycles until swallowing 
and cycle duration $(\mathrm{p}=0.000$; Table 1$)$. Much more muscle activity was needed for chewing peanut, melba toast and carrot than for chewing an equivalent volume of cheese or cake (Figure 1). The number of chewing cycles until swallowing cake was significantly lower than for swallowing cheese and melba, whereas cheese and melba were swallowed at a significantly lower number of cycles than peanut and carrot (Table 1 and Figure 1$)(\mathrm{p}<0.05)$. The average duration of a chewing cycle was shortest for carrot and peanut, whereas cheese and cake had the longest duration

TABLE 1- Influence of foods and fluids on chewing physiology parameters

\begin{tabular}{|c|c|c|c|c|}
\hline & EMG amplitude (mV) & EMG area (mV.s) & $\begin{array}{l}\text { Number of cycles } \\
\text { until swallowing }\end{array}$ & Cycle duration (s) \\
\hline Food influence & $\begin{array}{l}F=101 \\
p=0.000\end{array}$ & $\begin{array}{l}F=61 \\
p=0.000\end{array}$ & $\begin{array}{l}F=96 \\
p=0.000\end{array}$ & $\begin{array}{l}F=41 \\
p=0.000\end{array}$ \\
\hline $\begin{array}{l}\text { Post-hoc test } \\
\text { Food influence }\end{array}$ & $\mathrm{ch}=\mathrm{ck} \ll<\mathrm{me}=\mathrm{cr}<\mathrm{pe}$ & $\mathrm{ch}=\mathrm{ck} \ll<\mathrm{me}=\mathrm{cr} \ll$ pe & ck $\ll<$ ch $=$ me $\ll<$ pe $=$ cr & $\mathrm{cr}=$ pe $<\mathrm{me} \ll<\mathrm{ch}=\mathrm{ck}$ \\
\hline Fluid influence & $\begin{array}{l}F=7.0 \\
p=0.002\end{array}$ & $\begin{array}{l}F=12.2 \\
p=0.000\end{array}$ & $\begin{array}{l}F=36 \\
p=0.000\end{array}$ & $\begin{array}{l}F=1.8 \\
p=0.18\end{array}$ \\
\hline Food/fluid Interaction & $\begin{array}{l}F=2.3 \\
p=0.038\end{array}$ & $\begin{array}{l}F=3.4 \\
p=0.004\end{array}$ & $\begin{array}{l}F=8.2 \\
p=0.000\end{array}$ & $\begin{array}{l}F=1.7 \\
p=0.15\end{array}$ \\
\hline
\end{tabular}

${ }^{a}$ ch: cheese; ck: cake; me: melba toast; cr: carrot; pe: peanut

b $=:$ p $>0.05 ;<: p<0.05 ;<<: p<0.01 ;<<<: p<0.001$

TABLE 2- F- and p-values of the effects of fluid addition on chewing physiology parameters for each of the 5 foods

\begin{tabular}{|c|c|c|c|c|}
\hline & EMG amplitude (mV) & EMG area (mV.s) & $\begin{array}{l}\text { Number of cycles } \\
\text { until swallowing }\end{array}$ & Cycle duration (s) \\
\hline fluid influence & $\begin{array}{l}F=0.9 \\
p=0.45\end{array}$ & $\begin{array}{l}F=1.7 \\
p=0.20\end{array}$ & $\begin{array}{l}F=0.5 \\
p=0.70\end{array}$ & $\begin{array}{l}F=4.0 \\
p=0.020\end{array}$ \\
\hline $\begin{array}{l}\text { Carrot } \\
\text { Post-hoc test }{ }^{a, b}\end{array}$ & $w o=w 5=w 10 \quad w 5=a 5$ & $w o=w 5=w 10 \quad w 5=a 5$ & $w o=w 5=w 10 \quad w 5=a 5$ & wo $<w 5=w 10 \quad w 5=a 5$ \\
\hline $\begin{array}{l}\text { Cheese } \\
\text { fluid influence }\end{array}$ & $\begin{array}{l}F=1.5 \\
p=0.25\end{array}$ & $\begin{array}{l}F=0.4 \\
p=0.68\end{array}$ & $\begin{array}{l}F=7.5 \\
p=0.001\end{array}$ & $\begin{array}{l}F=3.0 \\
p=0.061\end{array}$ \\
\hline $\begin{array}{l}\text { Cheese } \\
\text { Post-hoc test }\end{array}$ & $w 0=w 5=w 10 \quad w 5=a 5$ & $w o=w 5=w 10 \quad w 5=a 5$ & $w o>>$ w5 = w10 w5 = a5 & wo $=w 5=w 10 \quad w 5=a 5$ \\
\hline $\begin{array}{l}\text { Melba } \\
\text { Fluid influence }\end{array}$ & $\begin{array}{l}F=7.2 \\
p=0.001\end{array}$ & $\begin{array}{l}F=10.8 \\
p=0.000\end{array}$ & $\begin{array}{l}F=46.9 \\
p=0.000\end{array}$ & $\begin{array}{l}F=0.8 \\
p=0.46\end{array}$ \\
\hline $\begin{array}{l}\text { Melba } \\
\text { Post-hoc test }\end{array}$ & $w o>$ w5 = w10 w5 = a5 & wo $>>$ w5 > w10 w5 = a5 & wo $>>>$ w5 > w10 w5 = a5 & wo $=w 5=w 10 \quad w 5=a 5$ \\
\hline $\begin{array}{l}\text { Peanut } \\
\text { Fluid influence }\end{array}$ & $\begin{array}{l}F=2.1 \\
p=0.11\end{array}$ & $\begin{array}{l}F=6.3 \\
p=0.002\end{array}$ & $\begin{array}{l}F=7.1 \\
p=0.001\end{array}$ & $\begin{array}{l}F=5.9 \\
p=0.002\end{array}$ \\
\hline $\begin{array}{l}\text { Peanut } \\
\text { Post-hoc test }\end{array}$ & $w 0=w 5=w 10 \quad w 5=a 5$ & wo $>$ w5 > w10 w5 = a5 & $w 0>>$ w5 = w10 w5 = a5 & wo $=w 5=w 10 \quad w 10>a 5$ \\
\hline $\begin{array}{l}\text { Breakfast cake } \\
\text { Fluid influence }\end{array}$ & $\begin{array}{l}F=3.2 \\
p=0.037\end{array}$ & $\begin{array}{l}F=5.0 \\
p=0.009\end{array}$ & $\begin{array}{l}F=18.0 \\
p=0.000\end{array}$ & $\begin{array}{l}F=0.7 \\
p=0.54\end{array}$ \\
\hline $\begin{array}{l}\text { Breakfast Cake } \\
\text { Post-hoc test }\end{array}$ & $w o>w 5=w 10 \quad w 5=a 5$ & wo $>>$ w5 = w10 w5 = a5 & wo $>>$ w5 = w10 w5 = a5 & $w o=w 5=w 10 \quad w 5=a 5$ \\
\hline
\end{tabular}

a wo: without fluid; w5: $5 \mathrm{~mL}$ water; w10: $10 \mathrm{~mL}$ water; a5: $5 \mathrm{~mL} \alpha$-amylase solution.

${ }^{b}=:$ p $>0.05 ;<: p<0.05 ;<<: p<0.01 ;<<<: p<0.001$ 
(Table 1)

Adding fluid to the foods had a significant influence on muscle activity (melba, peanut, and cake), and on the number of cycles until swallowing (cheese, melba, peanut, and cake; Table 2 and Figure 1) $(\mathrm{p}<0.05)$. Less EMG was needed for chewing when a fluid was added. The type of fluid (water or $\alpha$-amylase) had no influence on the muscle activity and number of cycles ( $p>0.05)$, whereas the increase in volume (from $5 \mathrm{~mL}$ to $10 \mathrm{~mL}$ water) significantly decreased muscle activity (melba and peanut) and number of cycles (melba).

During the successive chewing strokes, muscle activity and chewing cycle duration may change due to modifications in the food bolus. It was found that food type had a significant influence on the changes in muscle activity

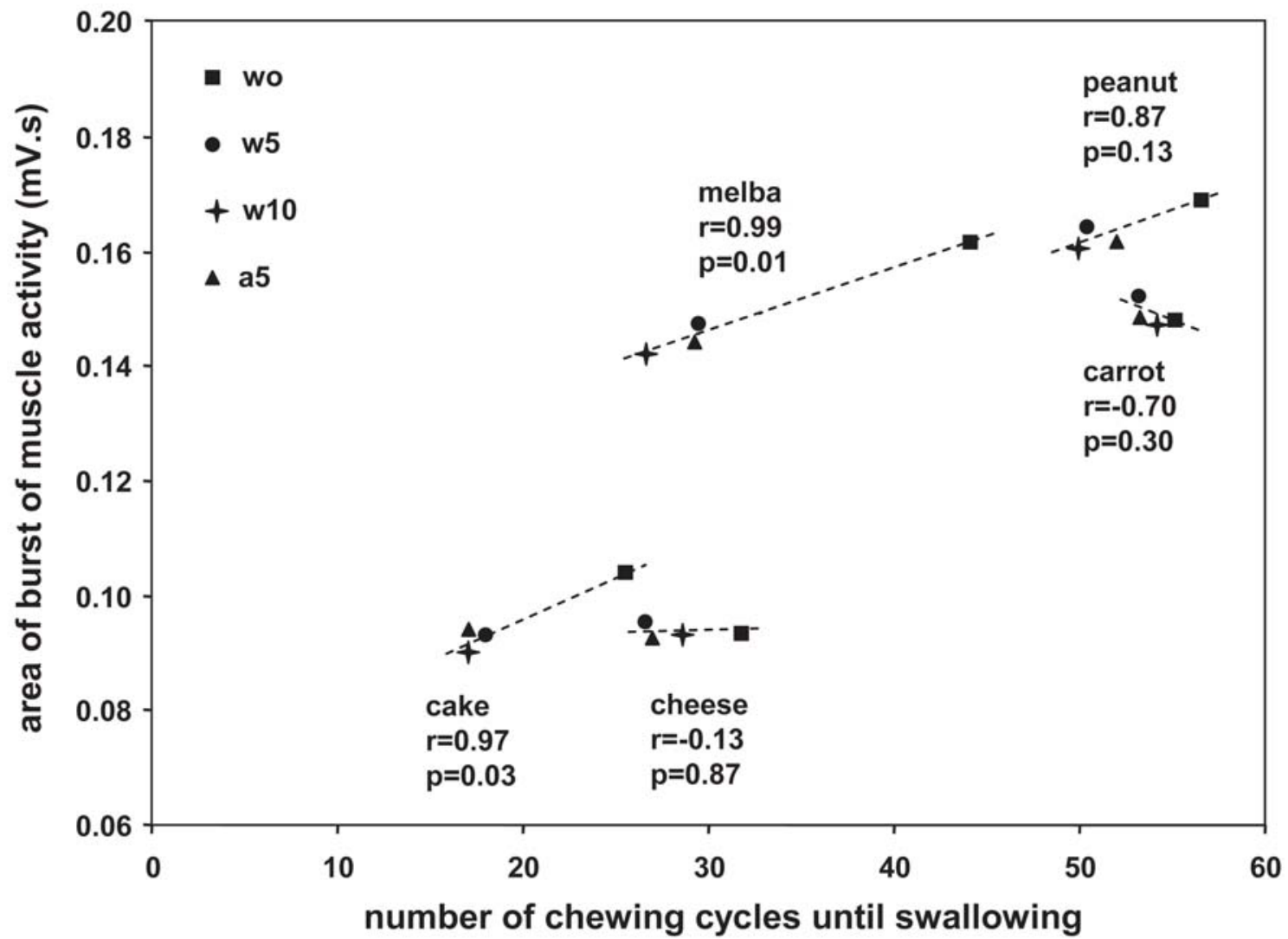

FIGURE 1- Means for muscle electromyographic activity area and number of chewing cycles for the different foods and fluids. wo: without fluid; w5: $5 \mathrm{~mL}$ water; w10: $10 \mathrm{~mL}$ water; a5: $5 \mathrm{~mL} \alpha$-amylase solution

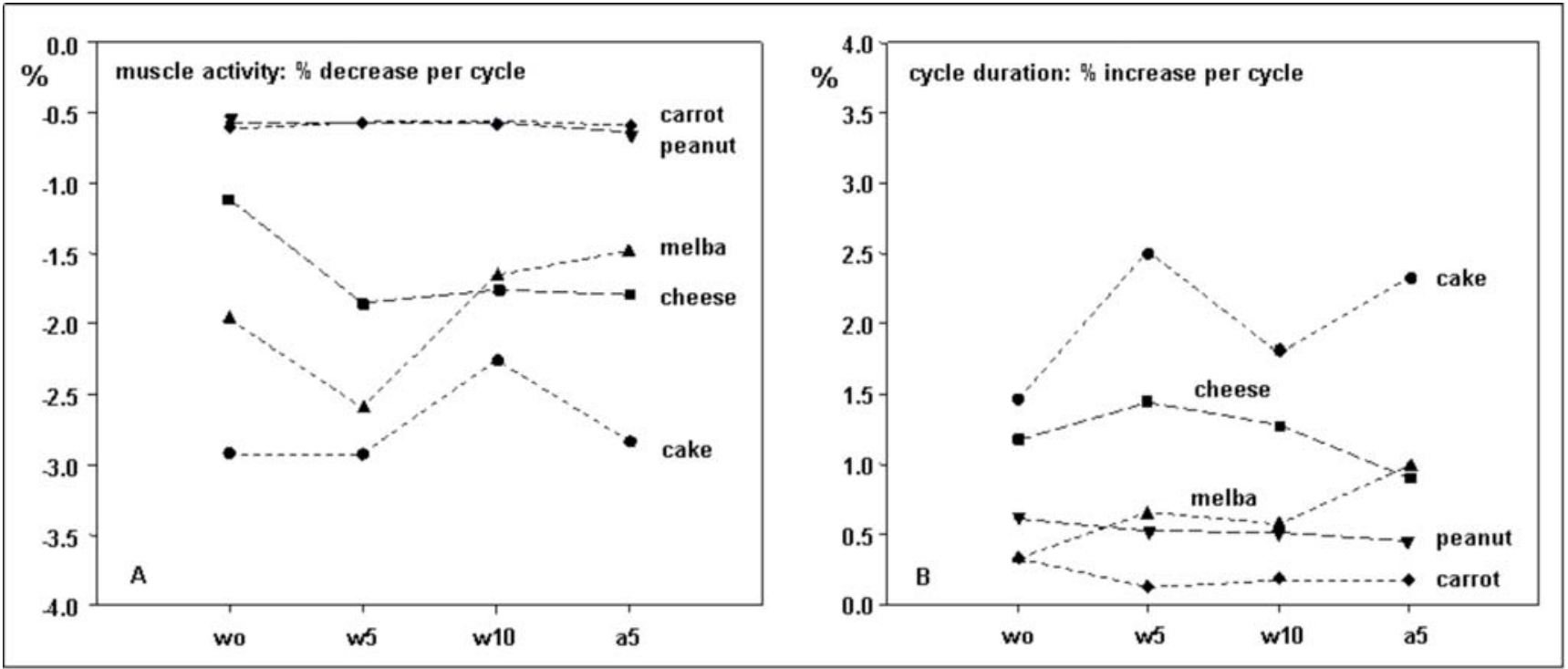

FIGURE 2- Percentage decrease in muscle activity and cycle duration per cycle during chewing for the different foods and fluids. wo: without fluid; w5: $5 \mathrm{~mL}$ water; w10: $10 \mathrm{~mL}$ water; a5: $5 \mathrm{~mL} \alpha$-amylase solution 
$(p<0.001)$ and in cycle duration $(p<0.001)$, whereas fluid addition had no significant influence ( $\mathrm{p}>0.05)$. For all foods, muscle activity significantly decreased during chewing. The decrease in the amplitude of muscle activity per chewing cycle ranged from $0.5 \%$ (peanut and carrot) to nearly $2 \%$ (melba, cheese and cake) (Figure 2). The duration of the chewing cycles increased throughout the chewing process (Figure 2) and this increase was significant for all foods $(\mathrm{p}<0.05)$ except for carrot. The increase in cycle duration ranged from $0.5 \%$ per cycle (carrot, peanut and melba) up to about $1.5 \%$ per cycle (cheese and cake).

\section{DISCUSSION}

The findings of the present study are of clinical significance because it shows that people suffering from dry mouth problems may benefit from fluid addition to foods. Large differences were observed with respect to muscle activity (amplitude and burst area), number of cycles until swallowing and chewing cycle duration for the 5 different foods. These differences are due to the fact that the foods varied largely in hardness (yield point), dryness (percentage water) and fatness (percentage fat $)^{5}$. The results obtained for the number of chewing cycles until swallowing were similar to those found for the same types of foods in a recent study ${ }^{5}$. Dry and hard products required more chewing cycles before swallowing. More time is needed to fragment the food and to add enough saliva to form a cohesive bolus suitable for swallowing ${ }^{2}$. The largest muscle activities were observed for the foods with the highest yield forces (peanut, melba and carrot), which concurs with the findings of previous reports ${ }^{17,18}$. The decrease in muscle activity during chewing was more accentuated for cake and melba, which are foods that easily absorb water and are thus softened. Our results are consistent with those of previous studies ${ }^{14}$. The average cycle duration was significantly shorter for carrot and peanut $(0.67 \mathrm{~s})$ than for cheese $(0.77 \mathrm{~s})$ and cake $(0.82 \mathrm{~s})$. Thus, foods that are relatively difficult to chew (peanut and carrot) are chewed at a higher chewing rate than foods that are easily chewed. Our results are in agreement with those previous investigations on the relationship between chewing rate and food hardness ${ }^{1,10,24}$. However, it has been shown that food hardness does not influence the chewing rate for chewing gum ${ }^{3}$ and silicone rubber $^{13}$. It was observed that chewing cycle duration increased during the chewing process. Thus, when food softens during chewing, cycle duration increases. Similar results have been reported for elastic model foods ${ }^{14}$.

Fluid addition had a significant effect on muscle activity for melba, cake, and peanut, as well as on the number of cycles until swallowing for melba, cake, peanut, and cheese. Figure 1 shows the influence of both food and fluid on muscle activity and number of chewing cycles. It is clear that the influence of fluid addition is much smaller than the influence of food. The added fluids had a larger influence on the number of chewing cycles until swallowing than on muscle activity. The largest effect of fluid on muscle activity and swallowing was observed for melba and cake. This fact is obviously related to the dryness of these foods. The chewing variables related to peanut were also significantly affected despite the fact that peanut has a large fat percentage (about 50\%). Apparently, the additional water facilitates the formation of a swallowable bolus ${ }^{20}$. Fluid addition had no influence on EMG activity and number of chewing cycles for carrot. This may be due to the large percentage $(90 \%)$ of water in carrot ${ }^{5}$. Adding $5 \mathrm{~mL}$ water caused a significant effect EMG activity and swallowing threshold for melba and peanut. No significant differences, however, were found between water and $\alpha$-amylase. Apparently, the $\alpha$-amylase already present in the mouth was sufficient to adequately break down the starch.

\section{CONCLUSIONS}

Fluid addition significantly decreased muscle activity and swallowing threshold for melba and cake, but had a less accentuated effect on peanut. Melba and cake are dry products, which require enough saliva to be added to form a coherent bolus safe for swallowing. Chewing of fatty (cheese) and wet (carrot) products was not influenced. The effect of $\alpha$-amylase solution on chewing physiology was similar to that of water. Doubling the volume of tap water had a larger effect than adding $\alpha$-amylase to the water. Thus, it may be suggested that the main effect of fluids is dilution. The findings of this study are relevant to improve patients' quality of life and aid the management of chewing and feeding disorders caused by hyposalivation.

\section{ACKNOWLEDGEMENTS}

This work was supported by the University Medical Center Utrecht and the Netherlands Institute for Dental Sciences. Special thanks to Prof. Dr. A. van Nieuw Amerongen (Oral Biochemistry, ACTAAmsterdam) for his advice on áamylase. One of the authors (LJP) received a scholarship from CAPES - Brazil.

\section{REFERENCES}

1- Ahlgren J. Mechanism of mastication. Acta Odontol Scand. 1966;44(Suppl):1-109.

2- Anderson DJ, Hector MP, Linden RWA. The possible relation between mastication and parotid secretion in the rabbit. J Physiol. $1985 ; 364: 19-29$

3- Anderson K, Throckmorton GS, Buschang PH, Hayasaki H. The effects of bolus hardness on masticatory kinematics. J Oral Rehabil. 2002;29:689-96.

4- Engelen L, de Wijk RA, Prinz JF, Janssen AM, van der Bilt A, Weenen $\mathrm{H}$, et al. A comparison of the effects of added saliva, áamylase and water on texture perception in semisolids. Physiol Behav. 2003;78:805-11 
5- Engelen L, Fontijn-Tekamp FA, van der Bilt A. The influence of product and oral characteristics on swallowing. Arch Oral Biol. 2005;50:739-46.

6- Fontijn-Tekamp FA, van der Bilt A, Abbink JH, Bosman F. Swallowing threshold and masticatory performance in dentate adults. Physiol Behav. 2004;83:431-6.

7- Gavião MBD, Engelen L, van der Bilt A. Chewing behavior and salivary secretion. Eur J Oral Sci. 2004;112:19-24.

8- Gavião MBD, van der Bilt A. Salivary secretion and chewing: stimulatory effects from artificial and natural foods. J Appl Oral Sci. $2004 ; 12: 159-63$

9- Hector MP, Linden RWA. Reflexes of salivary secretion. In: Garrett JR, Ekström J, Anderson LC, editors. Neural mechanisms of salivary gland secretion. Basel: Karger; 1999. p. 196-217.

10- Hiiemae KM, Heath MR, Heath G, Kazazoglu E, Murray J, Sapper $\mathrm{D}$, et al. Natural bites, food consistency and feeding behaviour in man. Arch Oral Biol. 1996;41:175-89.

11- Hutchings JB, Lillford PJ. The perception of food texture - the philosophy of the breakdown path. J Texture Stud. 1988;19:103-15.

12- Julien KC, Buschang PH, Throckmorton GS, Dechow PC. Normal masticatory performance in young adults and children. Arch Oral Biol. 1996;41:69-75

13- Kohyama K, Hatakeyama E, Sasaki T, Dan H, Azuma T, Karita $\mathrm{K}$. Effects of sample hardness on human chewing force: a model study using silicone rubber. Arch Oral Biol. 2004;49:805-16.

14- Lassauzay C, Peyron MA, Albuisson E, Dransfield E, Woda A Variability of the masticatory process during chewing of elastic model foods. Eur J Oral Sci. 2000;108:484-92.

15- Levine MJ, Aguirre A, Hatton MN, Tabak LA. Artificial salivas present and future. J Dent Res. 1987;66:693-8.

16- Mackie DA, Pangborn RM. Mastication and its influence on human salivary flow and alpha-amylase secretion. Physiol Behav. 1990;47:593-5.

17- Mathevon E, Mioche L, Brown, Culioli J. Texture analysis of beef cooked at various temperatures by mechanical measurements, sensory assessments and electromyography. J Texture Stud. $1995 ; 26: 175-92$

18- Mioche L, Bourdiol P, Martin JF, Noël Y. Variations in human masseter and temporalis muscle activity related to food texture during free and side-imposed mastication. Arch Oral Biol. 1999;44:100512

19- Neyraud E, Peyron MA, Vieira C, Dransfield E. Influence of bitter taste on mastication pattern. J Dent Res. 2005;84:250-4.

20- Pangborn RM, Lundgren B. Salivary secretion in response to mastication of crisp bread. J Texture Stud. 1977;8:463-72.

21- Pedersen AM, Bardow A, Jensen SB, Nauntofte B. Saliva and gastrointestinal functions of taste, mastication, swallowing and digestion. Oral Dis. 2002;8:117-29.

22- Prinz JF, Lucas PW. Swallow thresholds in human mastication Arch Oral Biol. 1995;40:401-3.

23- Prinz JF, Lucas PW. An optimization model for mastication and swallowing in mammals. Proc R Soc Lond B Biol Sci. 1997;264:171521.
24- Steiner JE, Michman J, Litman A. Time sequence of the activity of the temporal and masseter muscles in healthy young human adults during habitual chewing of different test foods. Arch Oral Biol. 1974; 19:29-34.

25- Tabak LA, Levine MJ, Mandel ID, Ellison SA. Role of salivary mucins in the protection of the oral cavity. J Oral Pathol. 1982;11:117

26- van der Reijden WA, Veerman ECI, van Nieuw Amerongen AV. Shear rate dependent viscoelastic behavior of human glandular salivas. Biorheology. 1993;30:141-52.

27- Watanabe S, Dawes C. The effects of different foods and concentrations of citric acid on the flow rate of whole saliva in man. Arch Oral Biol. 1988;33:1-5. 